\title{
Investigation of crack development in concrete dams due to water level fluctuation during earthquakes
}

\author{
S. A. Neshaei ${ }^{1}$, M. K. Abadi ${ }^{2}$ \& R. Vahedzadegan ${ }^{3}$ \\ ${ }^{1}$ Faculty of Engineering, University of Guilan, Iran \\ ${ }^{2}$ Faculty of Architecture and Civil Engineering, \\ Islamic Azad University, Iran \\ ${ }^{3}$ Faculty of Industrial and Mechanical Engineering, \\ Islamic Azad University, Iran
}

\begin{abstract}
Water level fluctuation in concrete dams can have a significant effect on stressstrain behavior at different locations in the body of such structures. This effect is more pronounced when earthquake induced forces are present. Sefid-Rud dam, which is located in the northern part of Iran, has suffered from progressive crack development during the earthquake which occurred in that region in 1990. Creation of a longitudinal crack near the normal water level of the mentioned concrete dam while the reservoir was full has occurred. In this paper, using the data of the Rudbar-Manjil earthquake, the behavior of Sefid-Rud dam is modelled numerically. The relation between the water level and dimension of the crack is empirically estimated and verified using the real field measurements indicating a good agreement. Following the dynamical analysis of Sefid-Rud dam, the stressstrain counters are achieved indicating the critical points in the cross section of the concrete dam. Based on these results the location and dimensions of possible cracks are estimated and compared with the measured data available after the mentioned earthquake. The results are encouraging for further development of the proposed model to predict the location and estimate the dimension of progressive cracks in such conditions when the seismic forces due to earthquakes exist.

Keywords: Sefid-Rud dam, elasto-plastic, dynamic analysis, reservoir water level, stress-strain curve, crack.
\end{abstract}




\section{Introduction}

In recent centuries, many concrete dams have been affected by the earthquakes with magnitudes over than 6.5 on the Richter scale that their amount of damages was very high, including Shih-Kang dam in Taiwan (2001), Sefid-Rud dam in Iran (1994) and Hessing Fing Kiang in China (1962) [1]. One of the most important factors influencing the damages severities caused by the dynamic forces is the reservoir water level and the forces derived from it on the dam wall.

Sefid-Rud dam as one of the four large dams in Iran, a non-reinforced concrete buttress type, has been constructed on a river with the same name during 1958 and 1962. The dam's height and crest length are 106 and $425 \mathrm{~m}$, respectively; and it consists of 7 weight blocks and 23 stable blocks, which the length of each block is $14 \mathrm{~m}$. This dam with an initial reservoir volume of $1,800,000,000 \mathrm{~m}^{3}$ has been located on a basaltic and andesitic foundation in the city of Manjil, Guilan province. With respect to the high-seismicity potential of Central Alborz and its seismic history, the assessment and investigation of the dam's seismic behavior influenced by severe earthquakes is one of the major issues in engineering. Most of the dams that were constructed in the not-so distant past have linearly been calculated with the static-analytical method. Thus, these dams are always vulnerable to non-linear analysis and dynamic forces caused by the earthquake. Therefore, the assessment of these dams against the new forces are very important and effective.

In recent years, many studies have been conducted to make dynamic analysis of the concrete dams using the shaking tables in vitro [2, 3]. Although the scale and material used in the tests are debatable.

A dynamic analysis of the concrete dams has not yet been made regarding the earthquake's impact of the Sefid-Rud dam. In the literature, the critical stresses and their locations, increasing trend of stress and the dynamic forces exerted on the dam wall depend on the factors such as the dam geometry, concrete heterogeneity, the status of reservoir, the reservoir water level, the dam longevity and the characteristics of earthquake that must exactly be applied during modeling procedure of the dam [4].

\section{Non-linear behavior of concrete}

Tensile strength of concrete is one of the important factors influencing the nonlinear behavior of concrete. The tests conducted on the concrete specimens showed that in addition to the mechanical properties of the concrete constituents and the specimen dimensions, the loading speed impacts on the tensile strength of concrete. The results obtained from the studies conducted on the concrete specimens of Sefid-Rud dam, which were exposed to the static and dynamic loading in vitro, showed that the compressive and tensile strength of concrete represent a different behavior, and the concrete compressive and tensile strengths will be increased by increasing the strain rate. According to the split cylinder tests for tension strength, researchers reported that the proportion of tensile strength of 
concrete in the dynamic loading is almost 1.30,1.44 and 1.45 times larger than the tensile strength in the statistic loading [5].

\section{Non-linear concrete model}

The Drucker-Prager failure criterion is used for the non-linear concrete model.

$$
F\left(I_{1}, J_{2}\right)=a I_{1}+\sqrt{J_{2}}-K \text {. }
$$

where:

$K$ and $a=$ constant values dependent material properties that depend on the material adherence and the internal friction angle.

$I_{l}=$ the sum of main tensions in 3 dimensionality.

$J_{2}=$ deviatoric tension matrix.

If $F\left(I_{l}, J_{2}\right)=0$, there is no problem in the materials and they are not included in the elastic range, but if $F\left(I_{1}, J_{2}\right) \geq 0$, the materials lose their strength and will flow.

The relationship between coefficients $K$ and $a$ and Mohr-Coulomb parameters can be expressed as follows:

For the symmetric flow:

$$
\begin{aligned}
& a=\frac{\sin \varphi}{\sqrt{1+\frac{1}{3} \sin ^{2} \varphi}} \\
& k=\frac{C \cdot \cos \varphi}{\sqrt{1+\frac{1}{3} \sin ^{2} \varphi}}
\end{aligned}
$$

For the deviatoric and plain strains:

$$
\begin{gathered}
a=\sin \varphi \\
K=C \cdot \cos \varphi
\end{gathered}
$$

Therefore, in order to define the non-linear materials with Mohr-Coulomb and Drucker-Prager methods, it is enough to define the parameters $v, E, \varphi$ and $C$.

\section{Modeling and allocation of the environmental characteristics}

Two modeling methods can be used for modeling the dam and the reservoir water. The first is Lagrange-Lagrange method and the second is Euler-Lagrange method, which the former has been used in this paper. In Euler-Lagrange method, the main parameter of water element is pressure. Therefore, the hydrodynamic pressure can directly be obtained after analyzing the model.

\subsection{Lagrange-Lagrange method}

In this stage, for the dam-foundation-reservoir system, the dynamic equation of motion should be solved according to the nodal point displacements of finite element network as follows [7]: 


$$
M \ddot{u}+C \dot{u}+K u=F(t)
$$

where:

$M=$ mass matrix

$C=$ damping matrix

$K=$ stiffness matrix

$\ddot{u}=$ acceleration vector

$\dot{u}=$ velocity vector

$u=$ nodal point displacements of finite element network vector

$F(t)=$ external forces vector

According to Fig. 1, the boundary conditions of dam-foundation-reservoir system will be applied in the planes $R_{1}$ to $R_{5}$ as follows [7-9]:

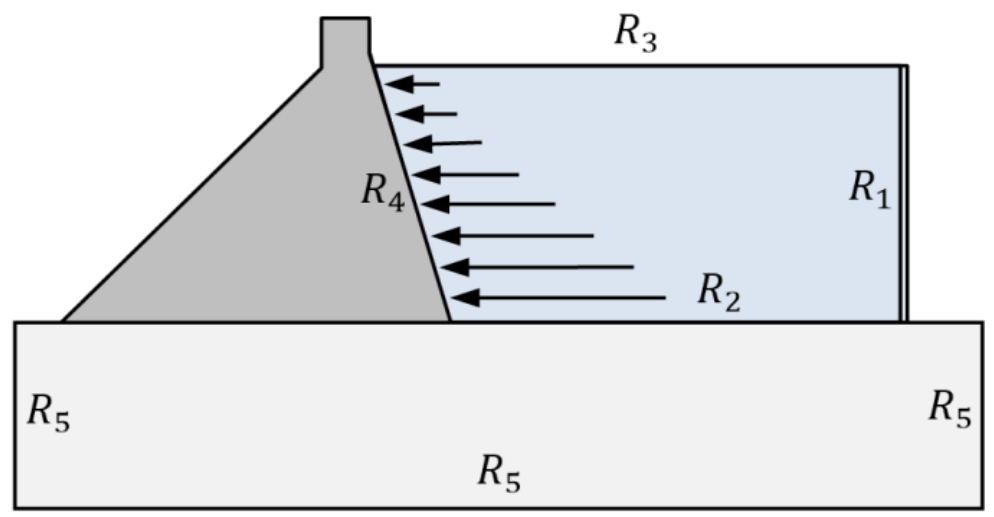

Figure 1: Dam-foundation-reservoir system and the method of distributing pressure throughout the dam body. A graphical representation of vector point.

\subsubsection{The boundary conditions for the dam-foundation-reservoir in Lagrange method}

In Fig. 1, at the upstream boundary of reservoir $\left(R_{l}\right)$, the boundary condition should be applied in order to meet the condition for passing the water pressure waves without any reflection. The depreciation matrix derived from these components can be written as follows $[8,9]$ :

$$
C_{M}=\rho_{w} \cdot C_{w} \int_{R_{1}}^{R_{n}} N^{T} n^{T} n N \cdot d r
$$

where:

$N=$ shape functions of reservoir parts at the boundary $\mathrm{S}_{1}$

$n=$ normal vector perpendicular to the boundary

$\rho_{w}=$ density of the fluid

$C_{w}=$ elastic wave velocity in the reservoir

$$
C_{w}=\sqrt{K_{B} / \rho_{w}}
$$




\subsection{Euler-Lagrange method}

In this section, for the structures' environment (dam and foundation), the dynamic equation of motion has been expressed in Eq. (6) in terms of nodal point displacement of structure [7-9].

The differential equation for the hydrodynamic pressure waves in the reservoir will follow the equations called the quasi-harmonic equations which are expressed as follows $[9,10]$ :

where:

$$
\begin{gathered}
\nabla^{\Gamma} K_{B} \nabla P-\rho_{w} \ddot{P}=0 \\
K_{B}=K_{B} l
\end{gathered}
$$

$\mathrm{I}=$ unit matrix

$p=$ the second derivative with respect to time

$\nabla^{T}=$ transpose operator $\nabla$

$\Gamma=$ internal surface of reservoir

Ritz-Galerkin's method was used to solve the above differential equation.

\subsubsection{The boundary conditions for the dam-foundation-reservoir system in Euler method}

The boundary conditions for the four boundaries of the reservoir are computed as follows [8-10]:

Boundary conditions for the wave propagation in the boundary $\left(R_{l}\right)$ are expressed as follows:

$$
\begin{gathered}
\frac{\partial P}{\partial n}=\frac{-1}{C_{w}} \dot{p} \\
-\int_{R_{1}} N^{T} \frac{\partial P}{\partial n} d r=\left(\frac{1}{C_{w}} \int_{R_{1}} N^{T} N d r\right) \dot{p}
\end{gathered}
$$

where:

$\dot{p}=$ the first derivative with respect to time

The integral inside the brackets will be expressed as $\mathrm{A}_{1}$ and the depreciation matrix is a diffusion one.

\section{Selection of element in the element formulation model}

Each element of the ANSYS software has different capabilities that have been determined in the input table for each element (the maximum capabilities for each element is 13). It can be made with the command KEYOPT. For example, with respect to the input table for the fluid element, if $\operatorname{KEYOPT}(2)=0$, then there is an interface between the element and structures, and the degrees of freedom will be $\mathrm{U}_{\mathrm{x}}, \mathrm{U}_{\mathrm{y}}$ and PRES, and if $\operatorname{KEYOPT}(2)=0$, then there is no interface between the element and structures and the degree of freedom will just be PRES. Therefore, we have two fluid elements (we select the element FLUID29 twice when selecting the fluid element): The first is the fluid element adhered to the dam and the second is $\operatorname{KEYOPT}(2)=1$ where there is no interface between the fulid elements of the reservoir and dam and $\operatorname{KEYOPT}(2)=0$. 
Since the analysis of gravity dam has been made in terms of the plane strain, we should use KEYOPT(3) = 2 for the element of PLANE82 which has been applied in the dam model (with respect to the input table for element in the guideline of ANSYS elements).

\section{Numerical analyses}

In the current study, the dynamic response of dam to the Modal and Harmonic analysis with the horizontal acceleration of $0.5 \mathrm{~g}$ and the vertical acceleration of $0.25 \mathrm{~g}$ is investigated. This acceleration is almost equal to the ground acceleration in the earthquake of Avaj (Qazvin) and the project acceleration in the reference [6] for comparing the results.

\subsection{Characteristics of analyzed dam}

Fig. 2 shows the geometric characteristics and boundary conditions. In this model, the damping factor of $5 \%$ has been used for the dam and reservoir. The length of reservoir and the width of crest were 200 and $10 \mathrm{~m}$, respectively.

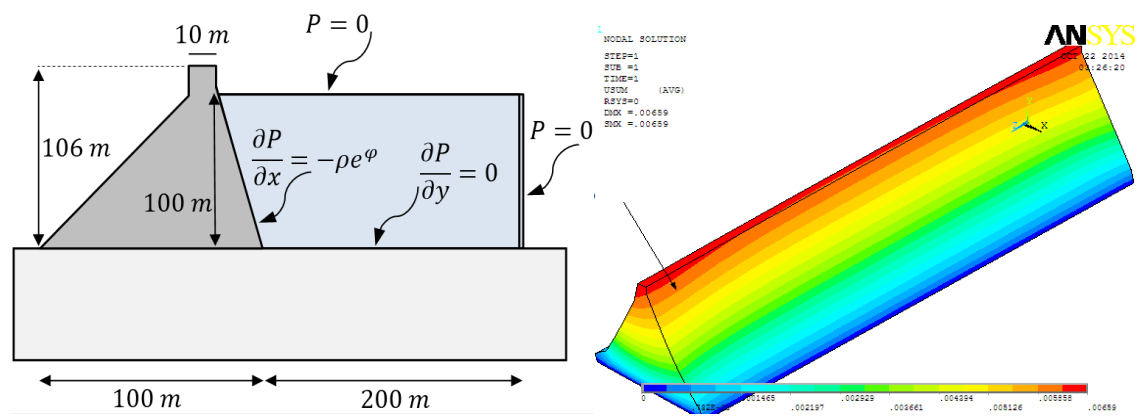

Figure 2: The dam-foundation-reservoir system and a graphical representation of the location of critical stresses and a general crack throughout the dam body.

\subsection{Characteristics of the concrete and water}

The materials properties are as follows:

The density of concrete $=0.255 \mathrm{t}-\mathrm{S}^{2} / \mathrm{m}^{4}$

The elastic modulus of concrete $=3.5 \mathrm{e} 6 \mathrm{t} / \mathrm{m}^{2}$

The speed of sound in water $=1435 \mathrm{~m} / \mathrm{s}$

The density of water $=0.1019 \mathrm{t}-\mathrm{S}^{2} / \mathrm{m}^{4}$

The compressive strength of concrete $=266 \mathrm{Ton} / \mathrm{m}^{3}$

The tensile strength of concrete $=15 \%$ of the compressive strength of concrete (with respect to the factors affecting it), thus its value will be $39.9 \mathrm{Ton} / \mathrm{m}^{3}$

Therefore, the values of $\mathrm{C}$ and $\varphi$ have been calculated as $43.21 \mathrm{Ton} / \mathrm{m}^{3}$ and $54^{\circ}$, respectively. 


\subsection{Modal analysis}

Fig. 3 shows the predominant mode (the first mode) of the ten water level and dam models with an empty reservoir.

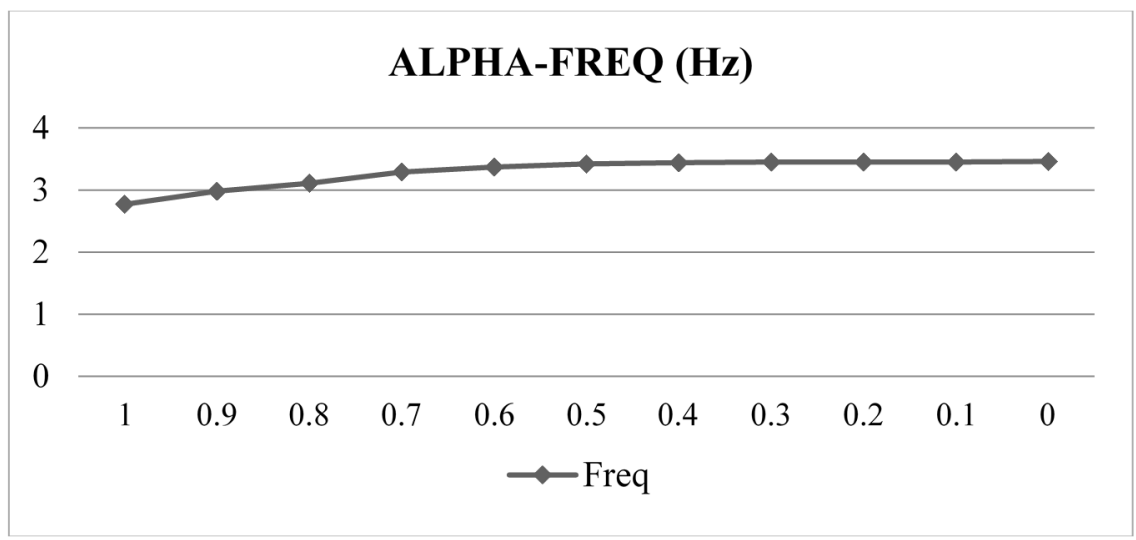

Figure 3: The first mode frequency. Changes in the reservoir water level relative to the reservoir height and changes in the frequency.

As can be seen in Fig. 3, the changes in frequency within the range of $0 \leq a \leq$ 0.5 are negligible and the frequency remains in the range of 3.4 and the first mode's frequency will be decreased more quickly by increasing the water level (a $>0.5)$.

\subsection{Harmonic analysis}

In order to conduct a harmonic analysis, the dam and reservoir system has been analyzed in the frequency range of $0 \mathrm{~Hz}$ to $10 \mathrm{~Hz}$. Five critical points of the dam have been selected to compare the results obtained from the models' harmonic analyzes:

$\mathrm{A}=$ Upstream heel

$\mathrm{B}=$ Downstream heel

$\mathrm{C}=\mathrm{A}$ point with the height of $2 \mathrm{H}$ in upstream

$\mathrm{D}=$ A point with the height of $2 \mathrm{H}$ in downstream

$\mathrm{E}=$ The point of slope variations in downstream

$\mathrm{H}=$ Height of dam

\section{Results and discussion}

The following results have been obtained from all of the analysis conducted in this paper. The following tables (Tables 1-6) indicate the maximum stress variations in the 5 points of the dam and the maximum dam crest's movement in 11 models. 
Table 1: Modified stresses in upstream heel $\left(\mathrm{T} / \mathrm{m}^{2}\right)$.

\begin{tabular}{|c|c|c|c|c|c|c|c|c|c|c|c|}
\hline Model & 1 & 2 & 3 & 4 & 5 & 6 & 7 & 8 & 9 & 10 & 11 \\
\hline A & 672.1 & 603.5 & 524.4 & 461.7 & 418.7 & 414.8 & 460.8 & 470.5 & 516.5 & 655.9 & 465.4 \\
\hline
\end{tabular}

Table 2: Modified stresses in downstream heel.

\begin{tabular}{|c|c|c|c|c|c|c|c|c|c|c|c|}
\hline Model & 1 & 2 & 3 & 4 & 5 & 6 & 7 & 8 & 9 & 10 & 11 \\
\hline B & 564.6 & 436 & 386.8 & 335.7 & 339 & 270.5 & 290.7 & 267.1 & 265.7 & 218.3 & 187.4 \\
\hline
\end{tabular}

Table 3: Modified stresses in upstream dam with the height of $\left(\mathrm{T} / \mathrm{m}^{2}\right) \mathrm{y} / 2$.

\begin{tabular}{|c|c|c|c|c|c|c|c|c|c|c|c|}
\hline Model & 1 & 2 & 3 & 4 & 5 & 6 & 7 & 8 & 9 & 10 & 11 \\
\hline $\mathrm{C}$ & 278 & 274 & 241 & 230.7 & 220.8 & 209.6 & 198.3 & 201.6 & 185.7 & 169.6 & 140.5 \\
\hline
\end{tabular}

Table 4: Modified stresses in downstream dam with the height of $\left(T / m^{2}\right) y / 2$.

\begin{tabular}{|c|c|c|c|c|c|c|c|c|c|c|c|}
\hline Model & 1 & 2 & 3 & 4 & 5 & 6 & 7 & 8 & 9 & 10 & 11 \\
\hline $\mathrm{D}$ & 267.7 & 265 & 228.5 & 202.5 & 194.3 & 181.2 & 172 & 170.6 & 133 & 121.5 & 111.1 \\
\hline
\end{tabular}

Table 5: Modified stresses in the point of downstream slope change near the crest $\left(\mathrm{T} / \mathrm{m}^{2}\right)$.

\begin{tabular}{|c|c|c|c|c|c|c|c|c|c|c|c|}
\hline Model & 1 & 2 & 3 & 4 & 5 & 6 & 7 & 8 & 9 & 10 & 11 \\
\hline $\mathrm{E}$ & 27.9 & 58 & 32.06 & 58.77 & 57.71 & 44.64 & 38.86 & 38.46 & 38.07 & 38.14 & 36.2 \\
\hline
\end{tabular}

Table 6: Modified horizontal movements of the dam crest $(\mathrm{cm})$.

\begin{tabular}{|c|c|c|c|c|c|c|c|c|c|c|c|}
\hline Model & 1 & 2 & 3 & 4 & 5 & 6 & 7 & 8 & 9 & 10 & 11 \\
\hline $\mathrm{U}_{\mathrm{X}}$ & 5.8 & 4.8 & 4.5 & 3.8 & 3.5 & 3.4 & 3.2 & 3 & 2.9 & 2.7 & 2.2 \\
\hline
\end{tabular}

In the most cases, the system response will be increased by increasing the period of dam composed system and dam-reservoir interaction (especially in the horizontal mobility). There is a direct relationship between its increase and the main frequency of reservoir. Generally, a significant error may be made (especially for high dams) if the interaction between dam and reservoir is accounted. Also, the dam flexibility can increase the system's period of vibration. Therefore, this parameter can increase the response too. As can be seen in the tables and Figs 4 and 5, almost all of the stresses are maximized when the reservoir is full. The stress of toe in the empty reservoir has suddenly been decreased due to the removal of water hydrodynamic force. For the dam model with a reservoir water level of $10 \mathrm{~m}$ in height, the stress under these conditions is not equal to the stress when the reservoir is full. When the water level of reservoir is decreased to approximately half of the previous level, the stresses are reduced to about $1 / 2 \mathrm{~m}$ of the dam height and then they will be fixed. According to Tables 7 and 8, the stress in the point of the crest slope variation will be increased. The cracks locations are equal to the cracks locations of static analysis [11]. The cracks in the heels will be developed to the upstream by increasing the loading frequency. The crack in the variation point of the crest slope is limited at this site, which exactly 
corresponded to the output of ANSYS program. The images for this analysis and the stress distribution inside the dam body are given in the following sections (Fig. $6)$.

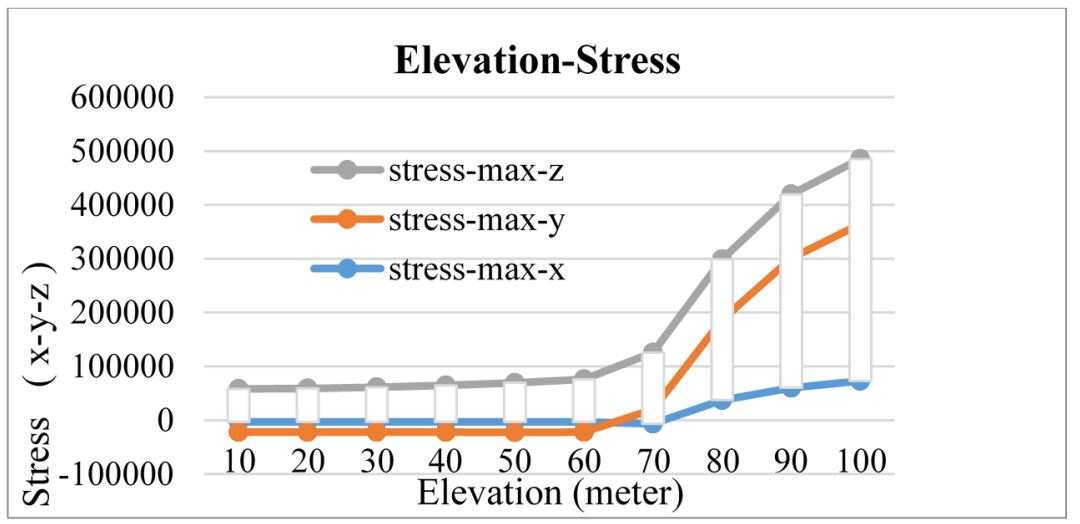

Figure 4: Immediate increase of the stress in the cross section of dam with the changes in water level up to10 $\mathrm{m}$.

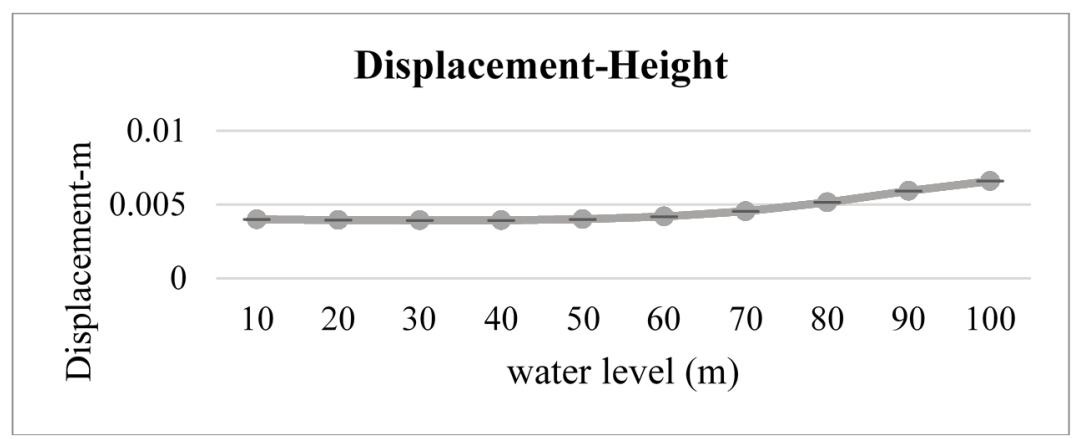

Figure 5: The dam crest movements with the changes in water level.

Analysis of static and dynamic pressures resulted from the water level changes of concrete dams is especially very important in the earthquake-prone areas. Given that Iran is an earthquake-prone country - especially by having the cities such as Roudbar and Manjil that Sefid-Rud dam has been constructed there and they were subjected to one of the biggest earthquake of the past century (in 1990) - this issue will be important more and more. Therefore, the current paper has investigated the impact of different fluctuations of water level into Sefid-Rud dam's reservoir and the seismic forces on the dam's body, and the critical surface tension into the dam's body has been determined in the various locations. The elastoplastic behavior of concrete dam has been assumed and the stress-strain curve of concrete has been used under these conditions. 
Table 7: Modified maximum and minimum stresses in the water level of $10 \mathrm{~m}$ (in height) from the reservoir bed to the dam crest.

\begin{tabular}{|c|c|c|c|c|c|c|c|}
\hline $\mathbf{h}(\mathbf{m})$ & $\begin{array}{c}\text { Strain } \\
\text { Min-x }\end{array}$ & $\begin{array}{c}\text { Strain } \\
\text { Max-x }\end{array}$ & $\begin{array}{c}\text { Strain } \\
\text { Min-y }\end{array}$ & $\begin{array}{c}\text { Strain } \\
\text { Max-y }\end{array}$ & $\begin{array}{c}\text { Strain } \\
\text { Min-z }\end{array}$ & $\begin{array}{c}\text { Strain } \\
\text { Max-z }\end{array}$ & $\begin{array}{c}\text { Displacement } \\
/ \mathbf{R}\end{array}$ \\
\hline $\mathbf{1 0}$ & -901184 & -3208.97 & -1840000 & -18956.1 & -459227 & 80368.8 & 0.003992 \\
\hline $\mathbf{2 0}$ & -935495 & -3219.29 & -1860000 & -18973.9 & -464965 & 81360.9 & 0.003953 \\
\hline $\mathbf{3 0}$ & -917399 & -3220.96 & -1930000 & -19008.3 & -481680 & 83358.1 & 0.003926 \\
\hline $\mathbf{4 0}$ & -917837 & -3200.34 & -2010000 & -19060.4 & -502262 & 86915.6 & 0.00393 \\
\hline $\mathbf{5 0}$ & -914891 & -3168.86 & -2070000 & -19126.2 & -516056 & 91830.4 & 0.003999 \\
\hline $\mathbf{6 0}$ & -910214 & -3079.44 & -2090000 & -19176.6 & -523413 & 98228.3 & 0.004182 \\
\hline $\mathbf{7 0}$ & -904828 & -6683.26 & -2110000 & 26733 & -525908 & 105526 & 0.004542 \\
\hline $\mathbf{8 0}$ & -899558 & 37340.8 & -2130000 & 149363 & -528484 & 112458 & 0.005153 \\
\hline $\mathbf{9 0}$ & -895209 & 60184.5 & -2170000 & 240738 & -542702 & 118698 & 0.005917 \\
\hline $\mathbf{1 0 0}$ & -892614 & 72813.2 & -2200000 & 291253 & -550964 & 121131 & 0.00659 \\
\hline
\end{tabular}

Table 8: Modified maximum and minimum strains in the water levels of $10 \mathrm{~m}$ (in height) from the reservoir bed to the dam crest.

\begin{tabular}{|c|c|c|c|c|c|c|c|}
\hline $\mathbf{h}(\mathbf{m})$ & $\begin{array}{c}\text { Strain } \\
\text { Min-x }\end{array}$ & $\begin{array}{c}\text { Strain } \\
\text { Max-x }\end{array}$ & $\begin{array}{c}\text { Strain } \\
\text { Min-y }\end{array}$ & $\begin{array}{c}\text { Strain } \\
\text { Max-y }\end{array}$ & $\begin{array}{c}\text { Strain } \\
\text { Min-z }\end{array}$ & $\begin{array}{c}\text { Strain } \\
\text { Max-z }\end{array}$ & $\begin{array}{c}\text { Displacement } \\
/ \mathbf{R}\end{array}$ \\
\hline $\mathbf{1 0}$ & -0.0000294 & 0.00000925 & -0.0000839 & -0.000000829 & -0.000000793 & 0.000013 & 0.003992 \\
\hline $\mathbf{2 0}$ & -0.0000326 & 0.00000666 & -0.0000845 & -0.000000824 & -0.00000079 & 0.0000166 & 0.003953 \\
\hline $\mathbf{3 0}$ & -0.0000324 & 0.00000363 & -0.0000867 & -0.000000824 & -0.000000787 & 0.0000183 & 0.003926 \\
\hline $\mathbf{4 0}$ & -0.0000334 & 0.00000294 & -0.0000904 & -0.000000825 & -0.000000772 & 0.0000184 & 0.00393 \\
\hline $\mathbf{5 0}$ & -0.0000348 & 0.0000023 & -0.0000929 & -0.000000825 & -0.00000074 & 0.0000179 & 0.003999 \\
\hline $\mathbf{6 0}$ & -0.000036 & 0.00000162 & -0.0000947 & -0.000000822 & -0.000000689 & 0.0000172 & 0.004182 \\
\hline $\mathbf{7 0}$ & -0.000037 & 0.00000155 & -0.0000962 & 0.0000012 & -0.000000629 & 0.0000168 & 0.004542 \\
\hline $\mathbf{8 0}$ & -0.0000379 & 0.00000163 & -0.0000973 & 0.00000672 & -0.000000571 & 0.0000168 & 0.005153 \\
\hline $\mathbf{9 0}$ & -0.0000385 & 0.0000017 & -0.000099 & 0.00000108 & -0.000000523 & 0.0000167 & 0.005917 \\
\hline $\mathbf{1 0 0}$ & -0.0000389 & 0.00000174 & -0.0000999 & 0.00000131 & -0.000000496 & 0.0000167 & 0.00659 \\
\hline
\end{tabular}
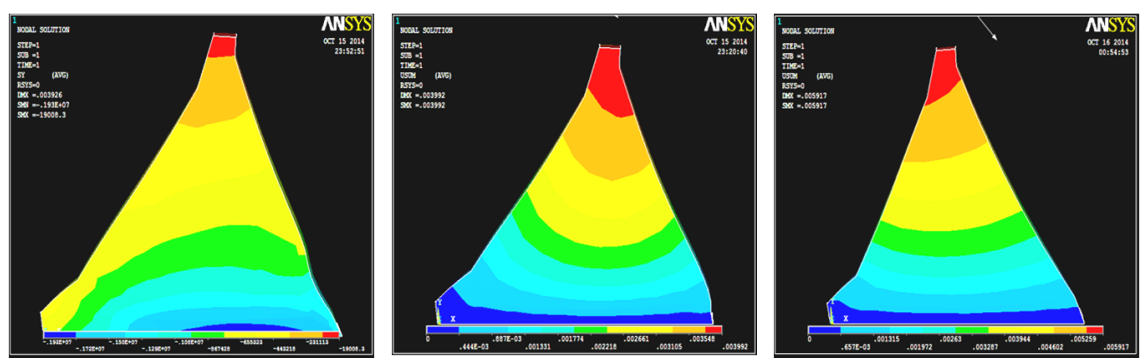

Figure 6: The color contours of strains in the cross section of Sefid-Rud dam (the red points show the general cracks). 


\section{References}

[1] ICOLD, "World Register of dams" Computerised version, Int. commission on Large Dams, Paris, 1998.

[2] Niwa, A. \& Clough, R. W, Nonlinearseismic Response of Arch Dams Earthquake Eng \& Struct. Dyn., 10, 1982.

[3] Pekau ,O. A .\& Lingmin, F, and Chuhan, Z, "Seismic Fracture or koyna Dam: Case Study” Earthquake Eng. \& Struct. Dyn., 24, 1995.

[4] Tinawi, R, Leger, P, Leclerc, M. and Cipolla, G. "Seismic Safety of Gravity dams: From shake lable experiments to numerical analysis" Journal of Structural Engineering, April 2000.

[5] Raphel, J. M. "Tensile Strength of concrete" ACI Journal, Vol. 81, No. 2, Mar-Apr, 1984.

[6] A Unified Approach to Stability, Bearing Capacity, Consolidation, Creep and Flow for Two and Three-Dimensional Simulations in GEOTECHNICAL PRACTICE.1. Th. Zimmermann, A. Truty, A. Urbanski, S. Commend \& K. Podles, Zsoil, pp. 30.

[7] Wilson, E. L. and Khalvati, M. "Finite elements for dynamic analysis of fluid-solid systems.” Int. J. Num. Meth. Eng., Vol. 19, 1983.

[8] Navayineya, B. and Ahmadei, M. T. "Hydrodynamic analysis of dam and reservoir using Lagrangian method.” I. J. of Eng. Science and Industrial University, Vol. 6, No. 1.

[9] Alijamshidi, D. Assessment of Lagrangian and Eulerian methods for determination of hydrodynamics pressures on concrete gravity dams under seismic effect. M.Sc. thesis, Civil Engineering Dept., Mazandaran University (in Persian), 2004.

[10] Vaseghi, Amiri, J. Nonlinear dynamic analysis of tensile-shear failure in gravity dams including hydrodynamic interaction due to seismic loads. $\mathrm{PhD}$ thesis, Tarbiyate Modares University (in Persian), 1997.

[11] EP 1110-2-12 Appendix B "Design example-Chopra's simplified method", 30 Sep. 1995. 